\section{Offsite HUB (Scotland): establishing a collaborative regional framework for knowledge exchange in the UK}

The UK has been identified as the standout construction market in Europe and is set to become Europe's largest construction market by 2030. However, UK construction productivity performance is regarded as weak with low skills levels considered to be a key contributory factor. Consequently, Offsite construction has been identified by UK Government as a vehicle for improving productivity levels if the skills deficiencies in this particular market segment can be addressed. A series of projects were therefore launched by the UK Commission for Employment and Skills (UKCES) to encourage an R\&D approach to skills and development application in the workplace. This paper reports on one of these research projects, a University and Industry collaboration between two of the largest offsite timber platform frame manufacturers in the UK. The paper explains how a needs analysis process was utilised to develop skills training content tailored to the immediate needs of the industry partners. It also explores how working with academia and a wider community of stakeholders allowed this training content to result in sector level impact via knowledge exchange activities and generic skills material creation. Finally, the novel approach of utilising 'Hoshin' planning to form a larger regional Offsite HUB (Scotland) Community of Practice, with a developed plan for collaboration aligned with international offsite research objectives, is also explained. This is particularly relevant given the recent UK Farmer review "Modernise or Die - time to decide the industry future", the most recent in a series of calls from government and other respected sources for improved levels of productivity and cultural change in the construction sector. The case study presented in this paper is evidence of success in mobilising industry through creating communities of practice to advance the construction sector regionally. It also provides a generalisable method that is reproducible by other university-industry cohorts in order to realise shared industry wide goals.

Keywords: skills; knowledge management; collaboration; closed panel timber frame

\section{Introduction}

Global construction output is expected towill grow by $85 \%$ to $\$ 15.5$ trillion worldwide by 2030, and of this increase, $70 \%$ is being led by 8 nations: China, US, India, Indonesia, UK, Mexico, Canada and Nigeria (HM Government, 2013; Global Construction
Formatted: Line spacing: 1.5 lines 
Perspectives and Oxford Economics, 2015). The UK economy, ranking number 5 out of the 8 in terms of construction output, moved out of recession in the last quarter of 2009 following six consecutive quarters of negative growth (House of Commons Library, 2010). The UK has now been identified as the "stand out construction market in Europe" and the only G7 Country to Move Up in Global Ranking for growth, and between now and 2030, is set to rise to become the world's sixth largest and Europe's largest construction market (Global Construction Perspectives and Oxford Economics, 2015). UK construction, which currently contributes £90bn annually to the UK economy, will therefore become increasingly more important in the global context. However, there have been consistent calls from government and other respected sources for improved levels of productivity and cultural change in the construction sector (Latham, 1994; DTI, 1998; Barker, 2004; MMC Cross Industry Group, 2006, HM Government, 2013), with the most recent of which is the Farmer Review of the UK Construction Labour Model (2016) report "Modernise or Die - time to decide the industry future". Farmer highlights the construction sector's low productivity and predictability, structural and leadership fragmentation, and financial fragility. These challenges are all underpinned by a dysfunctional training and recruitment process that are wrapped in a culture of declining trust and collaboration.

Offsite construction has been identified by the UK Government 2025 Construction Strategy (HM Government, 2013) as a vehicle for delivering the improvement targets set (see section 2.0). The offsite construction sector in the UK is however, currently estimated to only represent $7 \%$ of total construction output, equating to £1.5billion per annum (UKCES, 2013). Therefore, in order that offsite construction become a vehicle for construction delivery, it needs to operate at scale. Further, in order to scale, there is a need for change in construction culture including multi-skilling, interdisciplinary collaboration, and greater flexibility within a number of job roles (UKCES, 2013; Goulding \& Arif, 2013).

This paper reports on a case study methodology for creating a collaborative regional framework in Scotland of academic and industry partners to facilitate knowledge exchange. The framework was established via an initial skills focussed project with two key employers and two academic partners, and then expanded to capture further regional offsite players. The emphasis of the project was on timber offsite given the Scottish context (timber platform frame represents $75 \%$ of all new build houses in Scotland) (Timbertrends, 2013). By expanding the network of players, a regional strategy was then 
developed taking into consideration the wider UK and international context. The objective of this paper is therefore to:

- Demonstrate this process in order that it can be applied to other regions and contexts.

- Explain and evidence the benefits that can be ascertained from industry, academic and external organisations working in collaboration.

- Present a new regional framework model for collaboration with an emphasis of addressing skills challenges at varying levels (professional practice and competency) in order to facilitate cultural change and future international impact.

\section{UK Construction and the Productivity Challenge}

In 2004 the 'UK International Sectoral Productivity Performance', construction was regarded as "weak", measuring in bottom 5 of 'EU 15' countries (Campbell and Garrett, 2004). Prior to the recession this poor productivity and lack of innovation in the sector was sheltered by the health of the economy (Wolstenholme, 2009). Historically productivity has been identified by a number of UK Government initiatives as a driver for improvement (Latham, 1994; DTI, 1998; Barker, 2004; MMC Cross Industry Group, 2006). The Construction 2025 Industrial Strategy: Government and Industry Partnership (HM Government, 2013) set a target for 50\% faster delivery, 33\% lower costs, 50\% lower emissions and 50\% improvement in exports for the construction sector broadly. In addition, in the most recent Farmer Review (2016) the "extremely poor level" of productivity was highlighted as a "critical feature of the industry".

Construction productivity is affected by numerous factors (Horner, 1982; Olomolaiye et al., 1998) with skill levels and people development a key impact factor (Lavender, 1996; Naoum, 2001, Abdel-Wahab, 2008; The Boston Consulting Group, 2016; Green, 2016). The UK Commission for Employment and Skills (UKCES) identified low productivity as a challenge to be addressed (UKCES, 2014a) and in 2015 launched the UK Futures Programme (UKCES, 2015) to encourage an R\&D approach to skills and development application in the workplace.

Productivity Challenge 1 of 6, 'Addressing the skills deficiencies in the offsite construction sector', consisted of 5 projects (Table 1). This article is concerningconcerns the outcomes of Project 4, Offsite HUB Scotland, a university and industry collaborative 
project, with the aim to make this method of establishing a community of practice generalizable to other construction markets both within the UK and internationally.

[Insert Table 1 and Headline]

\section{Methodology}

The methodology applied to the overarching research work presented in this paper is as follows:

1. Review and Plan: Undertake a rigorous review of the construction sector challenges via available literature and relate this to how such challenges can be addressed via improved forms of delivery (offsite construction) and industry / academic collaborations taking lessons learned from other sectors. The literature review provided a contextual background for the pilot study to be performed and the topical foci of the pilot study (skills deficiencies). The literature review also provided the necessary approach: using a collaborative industry - academic framework via communities of practice theory and practice.

2. Pilot: Implement a pilot collaborative industry and academic framework to resolve an immediate challenge of skills deficiencies utilising complimentary partner knowledge and expertise. The approach would use both qualitative (interviews) and quantitative (questionnaires) methods for understanding the upskilling requirements of the industry partners and via the structured approach taken the challenges could be shared via the $3^{\text {rd }}$ party academic institutions demonstrating commonality and therefore facilitating collaboration given a "problem shared is a problem halved".

3. Scale / Internationalise: Build upon the established collaborative framework utilising the lean Hoshin Planning (Akao, 1994) process in order to create a shared strategic vision for the regional sector. This vision would then be underpinned with a follow-on interview process in order to develop an aggregated response to addressing the challenges with an associated plan of action for the framework. Consistently the findings from the process would be correlated with a wider international roadmap (Goulding, \& Arif, 2013) in order to facilitate alignment and therefore the opportunity to scale through convergence. 


\section{An Approach to University-Industry Collaboration and Fostering Wider Support}

University - industry collaborations have proven beneficial to both parties when strategically approached. Industry partners may benefit from the collaboration by way of technological development, managing the risk of development, gaining a forum for networking, realising human and capital development, and accessing expertise and facilities. The university is able to gain pathways to make their research and outreach directly applicable to industry, test the validity of theory toward practice, and realise greater impact than when creating and disseminating knowledge in isolation (Table 2) (UKCES, 2014b; Santoro \& Chakrabarti, 1999; Cunningham \& Link, 2014).

[Insert Table 2 and Headline]

In order to address the identified UK construction productivity challenges, an initial University - Industry knowledge transfer collaborative framework was established between two industry lead players and two complimentary academic institutions with a primary focus on facilitating upskilling in the offsite sector. The academic institutions were complimentary given their receptive research backgrounds of construction skills and offsite modern methods of construction.

The initial industry-university relationship was to derive skills content via knowledge management through the process of capturing, developing, sharing, and effectively using organisational knowledge (Davenport, 1994). Organisational knowledge is either explicit - able to be documented, clear, concise, and easily transferred; or tacit - embodied knowledge, undocumented, personal, individual, procedural or propositional knowledge that is learned by either rational or empirical sources (Carrillo et al, 2005). The academic input therefore provided the opportunity to develop a structure of understanding to the existing and disintegrated explicit knowledge on know-what, whilst uncovering tacit knowledge contained in the company's employees' know-how (Bigliardi et al, 2014). The approach taken was consistent with previous such studies discovered through literature and organisation content review, semi-structured interviews for maximum employee input, application of thematic analysis, and triangulation of the data via a feedback loop (Vernikos et al, 2013).

The longer-term view was to foster additional industry partners and widen the community of practice remit utilising a 'Hoshin Planning' technique, sometimes referred
Formatted: Line spacing: 1.5 lines 
to a Quality Function Deployment (Akao, 1994). Recommended by Strategem, consulting business strategists to the Scottish Hub, Hoshin Planning is normally employed internally within companies and organizations as a method for ensuring that the strategic goals of a company drive progress and action at every level (Tennant \& Roberts, 2001) and to transform the voice of the customer into engineering parameters for a product (Larsen et

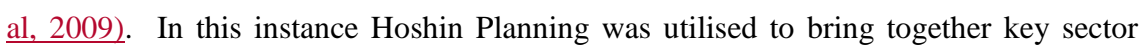
players to transfer knowledge. Knowledge transfer is a subset of knowledge management and is the practical task of transferring knowledge from one part of an organisation to another (Argote \& Ingram, 2000), or for this project transferring between a group of organisations. A key strategy in knowledge transfer is creating communities of practice - a deliberately established group that voluntarily forms to share knowledge through experiences, collective learning, and grow personally and professionally (Grisham \& Walker, 2006; Gao et al, 2008).

In this instance the community of practice to be formed was that of an Offsite HUB (Scotland) that would have a vision strategy. The vision scale was initially local but via the academic partners was aligned with the Offsite Production and Manufacturing Research Roadmap Report (Goulding \& Arif, 2013) considering the mature market prioritisations (Table 3).

[Insert Table 3 and Headline]

\section{The Offsite HUB (Scotland)}

\section{The Scottish Offsite Construction Sector}

The regional emphasis of the Scottish offsite sector is timber based offsite solutions, andmore specifically, timber platform frame construction. The majority of timber offsite is supplied to the Scottish housing sector and, to some extent, the wider growing UK market. Over the last 10-years the UK has built an average of 137,000 house per annum with estimates of up to 240,000 required to accommodate the population, demographic and net migration changes (CBI, 2014; The Lyons Housing Review, 2014). Currently Offsite timber frame represents $75 \%$ of the market in Scotland as compared to $18 \%$ in England (Timbertrends, 2013), the vast majority of which is open panel construction (externally lined with no inclusion of insulation, services, etc). This regional supply emphasis is due to historic market trends influenced by available skill sets, variance in building codes 
(Scotland is generally ahead of the rest of the UK with respect to thermal performance of the fabric) and climatic conditions, with a necessity to be wind and water tight quicker (Hairstans \& Sanna, 2017). Given the drive towards higher levels of productivity and sustainability at both Scottish and UK Government levels (Powell et al, 2015; ONS, 2015; The Scottish Government, 2013), Scottish timber offsite systems and more specifically enhanced panelised systems (inclusion of insulation and internal lining, windows and doors, external lightweight cladding or indeed services) (Fig. 1) has an opportunity for growth. To underpin this growth, the largest Scottish timber offsite producers, Stewart Milne Timber Systems (SMTS) and CCG(OSM) identified upskilling - teaching and learning additional skills - as a strategic need for their companies. Engaging in a collaborative project with university partners Edinburgh Napier University and HeriotWatt University via the UKCES UK Future Programme provided an opportunity for the development of training materials and an upskilling programme of work within and between the companies.

[Insert Figure 1 with caption]

\section{Building Collaboration}

SMTS and CCG are competitors and two of the largest companies in the timber frame market in Scotland, together holding around $40 \%$ of the market. Edinburgh Napier University was the lead University, calling principally on the services of the Centre for Offsite Construction + Innovative Structures (COCIS) with additional support from Heriot-Watt University given the institution's research experience in construction skills.

The project team of Edinburgh Napier, Heriot-Watt, SMTS and CCG in this case were responsible for the day-to-day delivery of the project. A larger steering group of stakeholders formed, collaborated and directed the work including the Construction Scotland Innovation Centre (CSIC), Skills Development Scotland (SDS), Construction Industry Training Board (CITB), Scottish Enterprise (SE), Scottish Development International, Link Housing Association (Link HA), UK Commission for Employment and Skills (UKCES), Equate, Colleges Scotland, Architectural Design Scotland (ADS), Scottish Government and Homes for Scotland.

Although the project duration was conducted over a relatively short timeframe of 7 months (September 2014 to April 2015), the academic, industry and wider stakeholder 
collaboration created the input and capacity to deliver on 3 areas of project activity including:

(1) Industry partner specific training material creation

(2) Generic training material creation

(3) Formation of the Offsite HUB (Scotland) Community of Practice

Industry partner specific training material creation

In order to assess the skills needs and create specific training material, the academic partners conducted a skills needs analysis of the companies. The analysis was initiated in order to codify and transfer skills knowledge through the process of capturing, developing, sharing, and effectively using organisational explicit and tacit knowledge.

The needs analysis consisted of the following: reviewing available company literature, including existing training material; conducting a series of interviews with relevant staff across the company structure to assess design, sales, production, technical, on-site erection, etc. from new start to director level; and surveying sub-contracted onsite staff. The analysis identified the immediate training requirements and allowed employee input into the process. This was important to facilitate buy-in and ensure compatibility with different skill set levels and approaches to learning.

Based on the findings of the needs analysis, CCG (OSM) and SMTS resolved to have a uniquely different skills content focus for each company. Although regarded as competitors, given the common need, the companies were willing to share the collateral content created.

- CCG (OSM) focussed on the creation of training content for their factory operators given their $£ 12 \mathrm{~m}$ investment in their Drumhead Road facility in Glasgow East Investment Park and their goal to offer full flexibility to their customers via the iQ system. The iQ systems comprises enhanced wall, floor and roof cassette panels capable of being fully closed internally and externally lined with insulation including the pre-installation of windows and doors and external finishes such as lightweight cladding.

- SMTS focussed on training material for the on-site assembly process for their British Board of Agreement (BBA) certified and Building Offsite Property Assurance Scheme (BOPAS) Sigma II Build System given its impending use, and their role as a delivery partner for the Bicester Eco Town Project. The long- 
term vision for the Bicester development plan is the provision of 6,000

sustainable new homes.

The training material was created with direct involvement from the industry partners primarily through the employment of graduate student interns to assist with project activities and content generation. The training content employed a range of techniques including written content, animations, videography, and mock-up demonstration samples. By employing a variety of techniques, the training content is engaging, can be used for a blended learning approach, and can be repurposed to serve a wider need. For example, the operative material created can be used to train others within the organisation on topics such as 'Design for Manufacture and Assembly' (DFMA) or for wider outreach and marketing purposes. It is worth noting that these project outputs align with People drivers of the Mature Market Prioritised Offsite Production and Manufacturing Research Roadmap (Table 3) (Goulding \& Arif, 2013).

Following the success of the project, CCG (OSM) has implemented an advanced offsite training process for their factory operatives and SMTS has launched a training academy at their Whitney facility with an emphasis on the site assembly of their offsite fabricated enhanced panelised systems (Fig. 2-4)

[Insert Figure $2-4$ with captions]

\section{Generic training material creation}

Running concurrently with the creation of the industry partner skills content, a series of events were hosted by Architectural Design Scotland (ADS) and the Construction Scotland Innovation Centre (CSIC). The events included contributions from the industry and academic project team members as well as other external agencies including BuildOffsite, Homes for Scotland (HFS) and Scottish Government. The content from these events was filmed and subsequently hosted on the ADS and CSIC websites for wider dissemination. Further, the content was spliced with the industry specific training material to produce generic videos explaining the "What", "Why" and "How" of Offsite Construction. The generic content has been embedded in an additional output, "Building Offsite: an introduction" (Hairstans et al, 2015), which is an up-to-date "active" and free downloadable publication that codifies the key terminologies of offsite construction including Design for Manufacture and Assembly (DfMA), standardisation, and mass 
customisation, to name a few. The publication outlines the advantages and disadvantages associated with offsite construction use, including barriers to uptake, and what needs to be considered when building in a factory environment. The publication also contains case study content (Table 4) provided by the industry partners to demonstrate successful utilisation of Offsite and sign posts the reader to other relevant documentation and online sources.

"Building Offsite: an introduction”, has been endorsed by the Royal Institute for British Architects (RIBA) for Continual Professional Development (CPD). The RIBA have 23,000 UK and 5,000 international chartered members, 11,000 student members and 700 associates. The publication has also been used for the delivery of the Royal Institute of Chartered Surveyor (RICS) and Construction Excellence CPD delivery. This demonstrates the external project value created by the collaboration and the benefits of the blended approach to content creation, particularly given the need for better refined skilled pathways or as the Farmer (2016) report states, “wide ranging career routes and prospects mapping” (Fig. 5). These project outputs again align with the People drivers of the Mature Market Prioritised Offsite Production and Manufacturing Research Roadmap (Table 3) (Goulding \& Arif, 2013) by “maximising training impact” and facilitating the “alignment of new job roles".

[Insert Table 4 with headline]

[Insert Figure 5 with caption]

Formation of the Offsite HUB (Scotland) Community of Practice

Offsite construction is internationally showing signs of steady growth and is regarded as being well established in North America, Europe, Japan, Australia, New Zealand and Malaysia with the most prominent emerging markets being China and India (Goulding and Arif, 2013). Given this international context, and the potential for long term scaling of the sector, Scottish Development International (SDI) and Scottish Enterprise (SE), in collaboration with the Construction Scotland Innovation Centre (CSIC), funded an Offsite Construction workshop that brought together key players from the Scottish offsite sector. The organisations attending the workshop included British Research Establishment (BRE), Stewart Milne Timber Systems, Oregon Timber Frame, Scotframe, Barratt, Alexander Timber Design, MAKAR and CCG(OSM). The 
objective of the workshop was to build consensus around a shared vision, the sector's uniqueness, key issues and constraints, and a strategy in order to gain momentum and scale. The Hoshin Planning technique was applied by an external facilitator in order to foster motivation for change and to demonstrate to the delegates that by working collaboratively in a community of practice across company lines, they could make a sector step change in the market.

The Hoshin Planning process articulated the strategy for the sector via the selection of the 'Vital Few' (VF) absolute priority goals agreed on by the delegates as critical to delivering the vision, "To be global leaders in Offsite Construction with a turnover of $£ 525 \mathrm{~m}$ by January 2018” (Table 5). The Vital Few were then aligned to a project plan for Scaling and Internationalisation (Table 6) and the collaborative framework extended to include an additional 5 organisations of MAKAR Construction, Carbon Dynamic, Alexander Timber Design, Oregon Timber Frame and Scotframe, regarded as the 'CORE' grouping of the Offsite HUB given their adoption of Offsite Modern Methods of Construction (MMC) (Table 7).

[Insert Tables 5 - 7 with headings]

\section{Project Legacy and extending the Collaborative Framework}

\section{Offsite (HUB) Model of Operation}

The Scottish Offsite Hub is a community of practice whereby the CORE group of companies collaborate to achieve a strategic direction of the "Vital Few" via competitor knowledge sharing. It is based on precedent communities of practice focused on offsite construction internationally, however its activities are customised to the specific needs of the Scottish and UK proper construction market and the regional offsite sector (Table 8).

[Insert Table 8 with heading]

The UKCES project demonstrated how collaboration between competitors is positive within a growth market when there are common goals. The Construction Scotland Innovation Centre (CSIC) is one of eight Scottish Funding Council (SFC) funded Innovation Centres set up to support industry led innovation. CSIC, via the 
Scottish academic community, developed a Memorandum of Understanding (MoU) that has been signed between the 7 'CORE' industry partners to underpin the establishment of the collaborative framework. The purpose of the framework is to allow the sharing of non-commercially sensitive knowledge and best practices with the view to creating a new business innovation model placing collaborative knowledge transfer at the heart of the enterprise.

The hypothesis (Fig. 6) behind the framework has been broadly developed on the principles of Modern Methods of Construction (MMC) (Barker, 2006) with the aim of improving business efficiency, quality, customer satisfaction, environmental performance, sustainability and the predictability of delivery timescales through empowering the use of better products and processes. Based on the derived hypothesis the following are the aims of the CSIC Offsite HUB:

- HUB members to identify future market and sector requirements and develop a plan of suitable actions to engage with relevant partners to plan a series of robustly managed activities.

- Undertake basic research activities which through innovation can be applied and therefore commercialised to benefit the sector.

- Exchange this knowledge between the partners and with the wider community to enhance skills throughout the supply chain and across the different business architectures in order to establish a change in culture with international outreach.

[Insert Figure 6 with caption]

\section{Phase 1 CORE Needs Analysis}

Over a period of 6 months ( $8^{\text {th }}$ of September 2015 to $19^{\text {th }}$ of January 2016), each of the CORE members were interviewed based on a questionnaire template derived by COCIS with input from CSIC, Scottish Enterprise (SE) and international collaborating partner University of Utah, Integrated Technology in Architecture Centre (ITAC). The qualitative interview therefore had academic input from the respective University partners as well as an industry and international sector perspective. The interviews were conducted in a conversational manner by COCIS with representation from collaborating partners as appropriate to ensure consistency of approach. The interviews covered the following key topics: Technical, Skills/Culture, Branding/Marketing, Business Models \& 
Strategies, and Internationalisation. On completion of the survey each industry partner was sent a copy for review and comment as well as a request to reflect on each of the topics discussed. The finalised interview information was then aggregated in order to capture the overarching qualitative sentiment of the group via generic statements and the surveyed ratings of key topics were averaged in order to rank them by importance. A CORE meeting was then held to discuss the generic statements in an open forum, to develop a consensus of approach, and allocate a series of prioritised actions going forward. The results of the qualitative needs assessment are as follows:

- Skills (\#1 Ranked, Rated 8.2/10): There is a need for improved skills pathways with an emphasis on CAD technicians, assemblers, project managers and estimators. The training requires to be focussed, quicker, more accessible, understandable and transferable to inform others such as the client or end user. With regards to estimator, a key training need is a way of improving the level of understanding on project and whole life cycle cost, and not just system cost.

- Branding \& Marketing (\#2 Ranked, Rated 7.9/10): There is a need for improved client and end user understanding of the offsite product offering that sells its higher value and level of finish to improve margin. This will aid in developing a secure project pipeline in order to enable the sector to scale. In many respects a collective response to this is required but given the variety and varying levels of media available the approach taken must be sophisticated and in most instances tailored to individual company needs and varying audiences.

- Business Models and Strategies (\#2 Ranked, Rated 7.9/10): Current procurement models that include land banking, speculative building to old UK code revisions (normally 3 to 5 years in arrears of when a building starts due the allowable period of consent) and traditional construction payment schedules, geared for onsite programmes of work, need to be challenged with a change to offsite delivery. In addition, a secure project pipeline is needed to allow investment and scaling to take place.

- Technical (\#4 Ranked, Rated 7.0/10): Given that the HUB Core membership represents a concentration of companies employing a timber offsite MMC approach, through incremental and systematic innovation, developed products have the potential to supply a high level of customised finish to meet with customer demand. However, the value proposition of this is not clearly defined given traditional construction 
business models and procurement methods. As a result, there is a need to devise a feedback loop capable of demonstrating the benefits of the Scottish offsite offering relative to key market drivers of quality, speed, performance (acoustics, thermal, indoor air quality, etc.) with respect to whole life cost and not just build cost.

- Internationalisation (\#5 Ranked, Rated 5.9/10): Although a few examples exist, there is limited scope for international export despite the available capacity and potential for Scottish and rest of the UK growth. However, there is the potential to export expertise and intellectual property (IP) and knowledge exchange with staff transfer, internships and learning journeys most commonly identified as ways of building international collaboration.

\section{Summary and Lessons Learned}

Industry and academic collaborations can create value for those involved on multiple levels if strategically planned and aligned with a wider group of stakeholders. However, their often requires to be a catalyst to bring the partners together. In this instance the catalyst was a shared challenge of addressing skills capacity in order to improve productivity. An independent review by SQW Consultants of this collaboration process identified a number of key lessons learned (Agur et al, 2015) (Table 7). Importantly, the influence of the academic and wider sector engagement via the UKCES and steering committee ensured an alignment to the wider generic training content creation and scaling and internationalisation objectives of the process. This is outlined via the key 'Tiers' of activity in Table 8. The role of the interns is also important to highlight as they served as a conduit for knowledge transfer between all of the partners involved and provided the needed capacity to deliver on project objectives.

[Insert Table 9 with headline]

[Insert Table 10 with headline]

Given the projections for market growth, and the inherent need for skilled capacity for offsite to scale to the levels predicted, collaboration through local frameworks and wider international networks will become increasingly more important in order to create communities or practice for local and international knowledge exchange. The creation of these frameworks requires collective strategies to be formed and the deployment of lean 
management techniques such as Hoshin planning, normally applied at organisation level, can be tailored for this purpose. Additionally, skills development should be considered inclusively and holistically throughout the supply chain, across the different business architectures, as well considering the knowledge and awareness of the end user, lenders, and insurers. This was reflected in the follow up Needs Analysis of the CORE Offsite HUB (Scotland) membership where Skills, Branding and Marketing, Business Models and Strategies were identified as the top 3 priority areas requiring attention.

The next steps of this effort are to continue to build the Offsite HUB (Scotland) community of practice and internationalise the effort with communities of practice in other countries principally via the Modular Offsite Construction International (MOCI), a grouping of international offsite academic and industry practitioners, whilst aligning with the 2013 CIB Offsite Production and Manufacturing - Research Roadmap. Important to this is maintaining industry involvement with a view to facilitating international collaboration. The findings of this study identify knowledge exchange as the most effective way of building international business collaboration with staff transfer, internships and learning journeys most commonly identified.

\section{Conclusions}

The research work of this paper sought to understand and pilot ways to scale theoffsite construction sector through collaboration given the need for improved levels of productivity and culture change most recently identified in the UK by the Farmer Review

(2016). A literature review determined that upskilling was needed in order to increase the offsite construction industry capability and creating a community of practice (hub) was an effective means for reaching shared goals among industry-academic partners.

It is apparent that the construction sector is fragmented regionally, nationally and internationally, therefore new approaches to collaboration need to be implemented. In this instance a combination of common problems with limited intellectual property concerns (upskilling), adapted strategic planning techniques (Hoshin Planning), government agency interventions (facilitation and funding), academic support (primarily knowledge management) and the opportunity for scale (UK and international market growth predications) combined to make this happen. Although this case study was concerning the region of Scotland, tThe approaches used and lessons learned from this example can be adapted and applied to other regional contexts through reciprocal regional frameworks or communities of practice. 
The challenges associated with fostering and operating a regional industryuniversity hub discovered through this example include concerns of intellectual property sharing, working to make tacit knowledge embedded within people and organizations explicit in order to be easily transferred, and identifying or creating an effective IT platform for knowledge transfer to name a few. Follow on research by the authors is being conducted to overcome these obstacles. Howeverfurther,-these progressive regional clusters, such as the one described in this paper, need to be linkedd in order to frame a global network which via the effective knowledge exchange techniques identified (staff transfer, internships and learning journeys) can start to instigate cultural change and via more progressive career pathways attract top talent to the built environment. Likewise, the authors recently launched the Built Environment Exchange, an international network of companies and universities that foster summer student research internship exchanges.

\section{Acknowledgements}

The authors wish to acknowledge the UK Commission for Employment and Skills (UKCES), Scottish Enterprise and the Construction Scotland Innovation Centre for the funding they have provided in supporting this work and the many industry and government partners that made the research possible. Thanks also to Strategem who facilitated the Hoshin Planning workshop. 


\section{References}

Abdel-Wahab, M. S., Dainty, A. R.J., Ison, S G., Bowen, P. and Hazlehurst, G. (2008) Trends of skills and productivity in the UK construction industry, Engineering, Construction and Architectural Management, Vol. 15 No. 4, 2008, pp. 372-382

Agur, M., Chipato, F., Thom, G., Breuer, Z. \& Hope, H. (2015) [c] Evaluation of UK Futures Programme: Offsite Hub (Scotland) UK Commission for Employment and Skills (UKCES):

https://www.gov.uk/government/uploads/system/uploads/attachment_data/file/469689/

UKFP_briefing_paper___Edinburgh_Napier_Offsite_Hub_case_study.pdf

Akao, Y. (1994) Development History of Quality Function Deployment. The Customer Driven Approach to Quality Planning and Deployment. Minato, Tokyo: Asian

Productivity Organization.

Argote, L.; Ingram, P. (2000). Knowledge transfer: A Basis for Competitive Advantage in Firms. Organizational Behavior and Human Decision Processes 82 (1): 150169. doi:10.1006/obhd.2000.2893.

Barker, K. (2006) Modern Methods of Construction (MMC) Executive Summary of Final Report - An examination of the barriers to the greater use of Modern Methods of Construction in the provision of new housing and the mechanisms to overcome them http://www.hbf.co.uk/?eID=dam_frontend_push\&docID=20329\&filename=MMC_Fina l_Draft.pdf Accessed 20 March 2016.

Barker, K (2004) Review of Housing Supply - Delivering Stability: Securing our Future Housing Needs, Final Report - Recommendations, Her Majesty’s Stationery Office, ISBN: 1-84532-010-7

Bigliardi, B., Galati, F., Petroni, A. (2014) How to effectively manage knowledge in the construction industry, Measuring Business Excellence, Vol. 18 Iss: 3, pp.57 - 72 
Campbell, A. \& Garrett, R. (2004) The UK skills and productivity agenda: The evidence base for the SSDA's Strategic Plan 2005-2008, Sector Skills Development Agency Research report 6 September 2004

Carrillo, P. M., Egbu, C. O., \& Anumba, C. J. (2005). Knowledge Management in Construction. Oxford: Wiley.

CBI (2014) Housing Britain - Building New Homes for Growth, http://news.cbi.org.uk/news/homes-for-growth/

Cunningham, J. A. \& Link, A. N. (2015) Fostering university-industry R\&D collaborations in European Union countries, International Enterprise Management Journal, pp 849 - 860

Davenport, Thomas H. (1994). "Saving IT's Soul: Human Centered Information Management". Harvard Business Review 72 (2): 119-131.

Department of Trade and Industry (DTI) (1998) Rethinking Construction - the Report of the Construction Industry Task Group, HMSO, URN 03/951

http://constructingexcellence.org.uk/wp-

content/uploads/2014/10/rethinking_construction_report.pdf Accessed 20 March 2016.

The Farmer Review of The UK Construction Labour Model (2016) "Modernise or die Time to decide the industry's future” http://www.cast-consultancy.com/wpcontent/uploads/2016/10/Farmer-Review-1.pdf

Gao, F., Li, M., Clarke, S. (2008) "Knowledge, management, and knowledge management in business operations", Journal of Knowledge Management, Vol. 12 Iss: 2, pp.3 - 17

Global Construction Perspectives and Oxford Economics (2015) Global Construction 2030 A global forecast for the construction industry to 2030, Global Construction Perspectives Limited, www.globalconstruction2030.com 
Goulding, J. \& Arif, M. (2013) Offsite Production and Manufacturing - Research Roadmap, International Council for Research and Innovation in Building and Construction (CIB) Publication 372, ISBN 978-90-6363-076-8 http://site.cibworld.nl/dl/publications/pub_372.pdf Accessed 20 March 2016.

Green, B. (2016), Productivity in Construction: Creating a Framework for the Industry to Thrive, The Chartered Institute of Building (CIOB), http://www.castconsultancy.com/wp-content/uploads/2016/10/Farmer-Review-1.pdf

Grisham, T. \& Walker, D. (2006) "Nurturing a knowledge environment for international construction organizations through communities of practice", Construction Innovation, Vol. 6 Iss: 4, pp.217 - 231

Hairstans, R. (2015) “Building Offsite: an introduction” Architectural Design Scotland, http://www.ads.org.uk/wp-content/uploads/Building-Offsite-An-Introduction.pdf

Hairstans, R. \& Sanna, F. (2017) A Scottish perspective on timber offsite construction, Offsite Architecture: constructing the future, R.Smith \& J.Quale (Eds).

Routledge/Taylor \& Francis, Book Chapter to be published.

HM Government (2013) Construction 2025: Industry strategy: government and industry partnership, URN BIS/13/955

Horner, M. and Duff, R. (2001), More For Less: A Contractors' Guide to Improving Productivity, CIRIA, London.

House of Commons Library (2010) Key Issues for the new parliament 2010 - House of Commons Library Research:

http://www.parliament.uk/documents/commons/lib/research/key_issues/Full-doc.pdf

Latham, M. (1994) Constructing the Team - Joint review of Procurement and Contractual Arrangement in the United Kingdom Construction Industry Final Report http://constructingexcellence.org.uk/wp-content/uploads/2014/10/Constructing-theteam-The-Latham-Report.pdf Accessed 20 March 2016 
Lavender, S. (1996), Management for the Construction Industry, Longman, Harlow.

Larson, Wiley J.; Kirkpatrick, Doug; Sellers, Jerry Jon; Thomas, L. Dale; Verma,

Dinesh, eds. (2009). Applied Space Systems Engineering. Space Technology. United States of America: McGraw-Hill. ISBN,978-0-07-340886-6.

Modern Methods of Construction Cross Industry Group (2006) MMC for the Provision of Housing: Barker 33 Review - Recommendations, Final report compiled by Tony Thomas of P. A. Thomas Management Systems and Prof. Ken Treadaway of Salford University

Naoum, S.G. (2001), People \& Organisational Management in Construction, Thomas Telford

Olomolaiye, P.O., Jayawardane, A.K.W. and Harris, F.C. (1998), Construction Productivity Management, Longman, Harlow.

ONS (2015) Quarterly National Accounts, Economic Outlook No.97, OECD, June 2015

Powell, R., Dunning, R., Ferrari, E. \& McKee, K. (2015) Affordable Housing Need in Scotland Final Report - September 2015, Shelter Scotland Publishing, London.

Quarterly National Accounts, ONS, June 2015; Economic Outlook No.97, OECD, June 2015

Santoro, M. and Chakrabarti, A. (1999) Building Industry - university research centers: some strategic considerations. International Journal of Management Reviews Volume 1 Issue 3. Pp.225-244.

The Boston Consulting Group (2016) Shaping the Future of Construction: A Breakthrough in Mindset and Technology, World Economic Forum in collaboration with the Boston Consulting Group, 4 May 2016.

\begin{tabular}{|l|}
\hline Formatted: Font: Times New Roman, $12 \mathrm{pt}$, Not Italic \\
\hline $\begin{array}{l}\text { Formatted: Line spacing: } 1.5 \text { lines, No bullets or } \\
\text { numbering }\end{array}$ \\
\hline Formatted: Font: Times New Roman, $12 \mathrm{pt}$ \\
\hline Formatted: Font: Times New Roman, $12 \mathrm{pt}$, Not Italic \\
\hline Formatted: Font: Times New Roman, $12 \mathrm{pt}$, Not Italic \\
\hline Formatted: Font: Times New Roman, $12 \mathrm{pt}$, Not Italic \\
\hline Formatted: Font: Times New Roman, $12 \mathrm{pt}$, Not Italic \\
\hline Formatted: Font: Times New Roman, $12 \mathrm{pt}$, Not Italic \\
\hline Formatted: Font: Times New Roman, $12 \mathrm{pt}$ \\
\hline Formatted: Line spacing: 1.5 lines \\
\hline
\end{tabular}


http://www3.weforum.org/docs/WEF_Shaping_the_Future_of_Construction_full_report -.pdf

The Lyons Housing Review (2014) Mobilising across the nation to build the homes our children need.

http://www.yourbritain.org.uk/uploads/editor/files/The_Lyons_Housing_Review_2.pdf

The Scottish Government (2013) Scotland's Sustainable Housing Strategy, APS Group Scotland, ISBN: 978-1-78256-648-9

Tennant, C. and Roberts, P. (2001) Hoshin Kanri: Implementing the Catchball Process. Long Range Planning V.34: 287-308.

Timbertrends (2013). Market Report 2012, Structural Timber Association, Alloa.

UK Commission of Employment and Skills (2013) Technology and skills in the Construction Industry Evidence Report 74, ISBN 978-1-908418-54-8

UK Commission for Employment and Skills (2014a) Growth through people - UKCES strategy 2014-17 and business plan 2014-15

UK Commission of Employment and Skills (2014b) Forging Futures - Building higher level skills through university and employer collaboration, ISBN: 978-1-84036-324-1

UK Commission of Employment and Skills (2015) UK Futures Programme: an introduction, UKCES Renaissance House, Adwick Park, Golden Smithies Lane, Wathupon-Dearne, South Yorkshire S63 5NB

https://www.gov.uk/government/collections/ukces-futures-programme-overview

Vernikos, V.K., Nelson, R., Goodier, C.I. and Robery, P.C. (2013), Implementing an offsite construction strategy: a UK contracting organisation case study. In: Smith, S.D., (Ed.) and Ahiaga-Dagbui, D.D. (Ed.), Proceedings of the 29th Annual ARCOM Conference, 2-4 September 2013, Reading, UK, Association of Researchers in 
Vernikes, V. K.. Nelson, R., Goodier, C. I. \& Roberty, P. G. (2013) Implementing an өffsite construction strategy: a UK contracting organisation case study, Proceedings of the 29th Annulal Association of Researchers in Construction Management (ARCOM)

Gonference, Reading, UK, 2nd-4th September 2013, pp. 667-677.

Wolstenholme, A. (2009) 'Never waste a good crisis: a review of progress since Rethinking Construction and thoughts for our future'. London: Construction Excellence. https://dspace.lboro.ac.uk/dspacejspui/bitstream/2134/6040/1/Wolstenholme\%20Report\%20Oct\%202010.pdf Accessed 20 March 2016. 